\title{
Analysis and Research on College Students' Selection Motives of Public Martial Art Course in Colleges and Universities
}

\author{
Xueni Ji \\ Nanchang Institute of Science \&Technology, Nanchang 330108, China
}

Keywords: course selection motives; martial art course; public course

\begin{abstract}
Through investigation and research among college students, their course selection motives and characteristics have been analyzed. In our country, public electives in colleges and universities do not only cater for all students' abilities, but also are suitable for their development. It is urgent to cultivate a kind of teaching mode which favors students' individual development and further perfect martial art course system of colleges and universities. Martial art course itself is an important subject in the public physical education of colleges and universities, and is also a popular subject among students. Through investigation, students have a certain understanding of selection motives of martial art course.
\end{abstract}

\section{Introduction}

As we all know, as a traditional culture of Chinese nation, martial art bears local customs of history. Its development has a profound historical and cultural background. With abundant participation, it has achieved a brilliant history of heyday. Although it has been affected by many factors in the course of history's development, there are also several restrictions. Especially, during the development and promotion, the culture between the ordinary and elite is not contrary. Martial art' development is based on national development. We will be able to constantly adapt to the changes of the times as well as create a favorable condition for our development by constantly improving the competitiveness of martial art and its economic level. Therefore, the education of martial art can not be ignored. At the same time, we are also suggested to correctly guide students to actively participate in martial art sports. Only in this way, can we make campus life more colorful and provide a more solid foundation for the development of martial art.

As the traditional culture, martial art is supposed to develop as well as carry forward Chinese traditional culture. In order to carry forward the culture, we are supposed to pay more attention to the special group of college students. Besides, marital art teaching can not be located only in levels like physical course or fitness. To carry forward national culture, we need to understand martial art teaching from the term of carrying forward national culture, especially increase its status in college education and constantly improve its teaching quality. Meanwhile, through research of martial art teaching condition of colleges and universities, we have explored the basic condition of martial art teaching in our country. At the same time, we are also able to find out unfavorable factors during martial art development according to teaching contents, methods, evaluation and students' purposes. Thus, we can put forward specific solutions for specific problems which may be encountered during students' study. Then, it will reduce the gap between actual teaching of martial art and students' expectation. To promote students' selective motives of martial art course, it is suggested to increase their interest in learning. Simultaneously, we also need to analyze the development of related resources, the actual atmosphere on campus martial art activities and so on, which will provide certain theoretical basis and relevant solutions for related departments of Shandong Province to take corresponding measures.

\section{Research Subjects and Methods}

Research subjects: We took students from a college as the research subjects and then explored their selective motives of public martial art course. 
Research methods: According to the actual investigation situations and purposes, we made corresponding questionnaires. The questionnaires concluded students' course selection motives, teaching contents, teaching methods, relationship between teachers and students, teaching faculty, equipments, assessment and so on. We delivered them on the random. A total of 200 questionnaires were distributed and 200 were recovered, so the recovery rate was 100 percent. Meanwhile, we also have screened these questionnaires continuously. There were 190 valid questionnaires, so the effective rate was $95 \%$.

\section{Analysis and Research of Results}

As we all know, interest is the best teacher. Students' learning motives are the only forces and subjective factors to promote development. They are built on the basis of learning and are the base to cultivate students' learning interest ${ }^{[2]}$. During research process, we found that students' selection motives were various. The foremost was to build up a good physique or was the purpose of attacking or defending which reaches $51.05 \%$. At the same time, motives of self-cultivation and personal hobbits respectively accounted for $30.52 \%$ and $16.5 \%$. Therefore, students learn martial art not only to strong the body, but also cultivate themselves. The ultimate motives were learning some simple, practical and defensive techniques. Their motives reflect that some disadvantages still exist in their cognition of education. Their understanding of martial art is superficial. They know little about numerous values and the profound cultural connotations of martial art.

In the teaching process, people know very little about martial art teaching. As we all know, teaching contents which are in line with students' reality are just favorable to cultivate their learning interest and learning habits. These conditions are quite important to cultivate students' lifelong study conviction ${ }^{[3]}$. According to the investigation and research, Public Martial Art Course of a college which was investigated contains martial art exercises, Tai Chi, juvenile boxing and other items, which shows that the college does not only enhance students' physique, but also consider for their long-term fitness interests. Especially items like Tai Chi do not only have long-term social benefits, but also favor students to better understand martial art and make a contribution for martial art' long-term development. During the investigation of teaching contents and teaching satisfaction, there were $49.47 \%$ students not satisfied, $47.37 \%$ students feeling general and $3.16 \%$ students choosing satisfaction. From students' choices, we can see that they are interested in items like free combat, Taekwondo and other defensive techniques which accounted for $59.76 \%$. Ratio of Taekwondo which was $48.78 \%$ also reached an all-time high. This phenomenon shows that offensive and defensive items like free combat, Taekwondo and other items are currently most popular among students. While for some unknown reasons, teachers ignore these items when they arrange teaching contents. The reasons that students were not satisfied with teaching contents are not merely the lack of pertinence but also the absence of effectiveness and entertainment, which can not promote students' course selection motives and decrease their learning interests. To some extent, this is also divorced from the actual needs of college students, so their course selection motives decline too.

In the process of martial art teaching, it is also quite necessary to teach related theories. However, during teaching, colleges always ignore this as well as the purpose of promoting martial art culture. We constantly enhance the understanding of martial art skills but neglect theories studying. The investigation shows that $68.42 \%$ students expressed teachers did not teach theoretical knowledge in class which means the absence of enough attention to theoretical course from colleges.

According to the survey, students who study marital arts almost know little about theoretical knowledge. There were only $4.21 \%$ students learn theories by themselves. There is a lack of feasibility for teachers to do theoretical guidance. Therefore, we are advised to continuously enhance the guiding contents of martial art theories.

From the survey of students' course selection motives, we get to know that a majority believed that knowledge taught in class is too general and there is not enough detailed explanation for theoretical researches. Meanwhile, 63.16\% students approved that appropriate teaching methods have been adopted according to their aptitude while 30.52\% students were against and thought that 
though teachers taught carefully, they failed to get good effects. 6.32\% students said they were not able to master movements taught in class. In Public Martial Art Course of our college, we take the teaching method of teachers' demonstration, students' imitation and practice. This is so called “duck-stuffing” type of teaching. It neglects the cultivation of students' marital art abilities and tends to be too programmed. Students' learning enthusiasm and initiative have not been given full play.

In the survey, we found that relationship between teachers and students are not ideally coordinated or even sometimes are opposite. For teachers, they need to seriously teach and strictly carry out the established syllabus and teaching plan which are also the teaching management rules and professional ethics that teachers should abide by. Students are curious, receptive to new things, averse to old things and eager for new things. However, in our college' public martial art course, the provided teaching contents no longer meet students' needs. Through conversations with students, we found that a majority prefer to communicate with each other during the break. The topics of conversations are mostly about how to do a certain movement, how to apply martial art movements learned in class in actual combat or something else from study or daily life. While students also reflected that there was less communications with teachers. Moreover, although there were 55.49\% students believed that teachers respected students' opinions and took teaching seriously, there were $48.78 \%$ students expressed that they were too shy to talk with teachers which resulted into deviation and lack of enough interaction and harmony between them. 2.2.5 assessment method needs to be improved

To do teaching assessment is an important step to realize scientific management of martial art teaching. It is also a measure for colleges to know students' learning conditions. They do assessment and evaluation according to established procedures and methods. In public marital arts course of our college, we do assessment from the perspectives such as routine completion, the quality of movements, drilling level and so on. This does not only indicate a single method to assess students' academic achievements but also reflect an influence from skill education views. Due to too much emphasis on technical skills level, students' individual differences and diverse learning enthusiasm are ignored which make this kind of assessment method fail to synchronize with the goal of cultivating students' lifelong physical education. Moreover, students pay most attention to their grades in examinations but do not care about how much they actually learn. This is also inconsistent with our educational objectives.

\section{Conclusion and Suggestions}

Although Public Martial Art Course of Texas College has been affected by various factors, the course is carried out smoothly. However, there are still many problems existing in students' course selection motives, teaching contents arrangement, interaction between teachers and students, assessment method and so on. Students' desire and need to learn martial art can not be well satisfied, so there are obstacles in promoting and popularizing martial art on campus.

(1) We are required to change our concepts, realize "people-oriented" conviction, innovate teaching mode and renovate teaching contents according to students' preferences, their needs and syllabus requirements. It is also necessary to reform teaching methods, adopt diversified and reasonable teaching measures, improve teaching quality as well as stimulate students' learning enthusiasm.

(2) We are advised to arrange theoretical course regularly, enhance education of Chinese traditional culture, renew assessment concepts, establish a fair and reasonable evaluation system and urge students to take part in extracurricular exercises voluntarily.

\section{References}

[1] Qu Zonghu, Houcheng, et al. On the Development and Conception of Physical Education Reform in Colleges and Universities in China [J]. China Sport Science, 1998.8 (4) 6-9. 
[2] Yang Tao. An Analysis of Current Teaching Situation and Countermeasures Research of Martial Art Selective Course in Colleges and Universities of Shandong Province [J]. Journal of Xi'an Institute of Physical Education, 2004. 5 (3) 96-99.

[3] Xie Yun, Shi Menglong. An Analysis of Teaching Situation and Countermeasures Research of Martial Art Selective Course in Colleges and Universities of Anhui Province [J]. Wushu Science, 2006.2 (2) 44-46.

[4] Mao Zhenming. On Physical Education Teaching [J]. Beijing: Higher Education Press, 2005. 